\title{
Surgical treatment of 125 patients with non-small cell lung cancer and chest wall involvement
}

Cordula C M Pitz, Aart Brutel de la Rivière, Hans R J Elbers, Cees J J Westermann, Jules $M M$ van den Bosch

\begin{abstract}
Background - The optimum operative procedure for lung cancer with chest wall invasion (T3) remains controversial. In this study results of en bloc resection and extrapleural dissection are reviewed to determine survival characteristics.

Methods - Between 1977 and 1993125 patients underwent surgery for primary non-small cell lung cancer with chest wall invasion. Patients with superior sulcus tumours, metastatic carcinomas, synchronous tumours, or recurrences were excluded. Extrapleural dissection was performed in 73 patients and en bloc resection (range $1-4$ ribs) in 52 . Resection was regarded as complete in 86 and incomplete in 39 patients. Actuarial survival time was estimated and risk factors for late death were identified.

Results - Hospital mortality was 3.2\% (n = 4). Estimated mean five year survival was $24 \%$ for all hospital survivors $(n=121)$, $11 \%$ for patients with incomplete resection, and $29 \%$ for patients having a complete resection. In patients who underwent complete resection mediastinal lymph node involvement and intrapleural tumour spill worsened the prognosis. Patients with adenocarcinoma had a better chance of long term survival. No relationship was found between survival and age, type of operative procedure, depth of chest wall invasion, and postoperative radiotherapy.

Conclusions - Both operative procedures show reasonable survival results. Incomplete resection, mediastinal lymph node involvement, and intrapleural tumour spill adversely influence survival.

(Thorax 1996;51:846-850)
\end{abstract}

Keywords: lung cancer, chest wall invasion, surgery, survival characteristics.

Surgical resection of non-small cell lung tumours and regional lymph nodes is the treatment of choice in the absence of distant metastases.

Of patients who undergo thoracotomy for lung cancer, $5-8 \%$ have chest wall invasion. ${ }^{1-3}$ The prognostic implication of this finding has been disputed and, formerly, thoracic wall involvement was considered to be irresectable and unfavourable. Good survival rates after en bloc resection were first reported by Coleman in $1947^{4}$ and Grillo et al in 1966, ${ }^{1}$ and subsequent reports have supported the surgical treatment of these tumours. ${ }^{3-7}$

In this retrospective study we have analysed our experience of 125 patients who underwent either en bloc resection or extrapleural dissection for non-small cell lung cancer involving the chest wall in order to evaluate these operative procedures and to determine survival characteristics.

\section{Methods}

Two thousand and nine patients with lung cancer underwent resection at our hospital between January 1977 and December 1993, of whom 125 patients $(6.2 \%)$ had a primary nonsmall cell lung cancer with chest wall invasion. Patients with distant metastases at presentation were excluded as were patients with superior sulcus tumours, synchronous tumours, metastatic carcinomas, and recurrent disease. All patients had tumour involvement of the parietal pleura or the skeletal muscles or ribs at pathological examination and were staged as T3 according to the TNM classification. ${ }^{8}$ Resection was regarded as complete when the surgeon felt certain that all visible disease was removed, resection margins were free at pathological examination, and the highest mediastinal lymph node was negative at microscopy. In some patients the tumour was opened by chance during surgery. This peroperative tumour spill was scored separately.

The ages of the patients ranged from 34 to 80 years with a mean of 62.4 years. There were 111 men, and 114 patients were smokers. Presenting symptoms included chest pain in 72 patients $(57.6 \%)$, cough in 58 patients $(46.4 \%)$, dyspnoea in 44 patients $(35.2 \%)$, and haemoptysis in 30 patients $(24 \%)$. Twenty four patients $(19.2 \%)$ were asymptomatic.

A histological or cytological diagnosis was obtained preoperatively in 103 patients $(82.4 \%)$. Bronchoscopy was diagnostic in 60 $(58.3 \%)$, percutaneous needle aspiration biopsy in $33(32.1 \%)$, cervical mediastinoscopy in six $(5.8 \%)$, rib puncture in two $(1.9 \%)$, and sputum cytology in two patients $(1.9 \%)$.

When invasion of the thoracic wall was proven preoperatively by pathological examination, en bloc resection was performed. Other-

Department of
Pulmonology
C C M Pitz
C J J Westermann
J M M van den Bosch
Department of
Thoracic Surgery
A Brutel de la Rivière
Department of
Pathology
H R J Elbers
Sint Antonius
Hospital,
3430 EM Nieuwegein,
The Netherlands
Correspondence to:
Dr JMM van den Bosch.
Received 11 April 1995
Returned to authors
17 November 1995
Revised version received
22 January 1996
Accepted for publication
28 February 1996


Table 1 Extent of pulmonary resection in all patients $(n=125)$ and those who underwent complete resection $(n=86)$

\begin{tabular}{|c|c|c|c|c|}
\hline \multirow[b]{2}{*}{ Operative procedure } & \multicolumn{2}{|l|}{ All patients } & \multicolumn{2}{|c|}{$\begin{array}{l}\text { Patients with complete } \\
\text { resection }\end{array}$} \\
\hline & $\begin{array}{l}\text { Extrapleural } \\
(n=73)\end{array}$ & $\begin{array}{l}\text { En bloc } \\
(n=52)\end{array}$ & $\begin{array}{l}\text { Extrapleural } \\
(n=45)\end{array}$ & $\begin{array}{l}\text { En bloc } \\
(n=41)\end{array}$ \\
\hline Pneumonectomy & 19 & 5 & 15 & 5 \\
\hline Bilobectomy & 1 & 1 & 1 & 1 \\
\hline $\begin{array}{l}\text { Lobectomy }+ \text { segmental or wedge } \\
\text { resection }\end{array}$ & 2 & 9 & 1 & 8 \\
\hline Lobectomy & 44 & 31 & 23 & 22 \\
\hline Segmental resection & 5 & 5 & 5 & 5 \\
\hline Wedge resection & 1 & 1 & 0 & 0 \\
\hline Bullectomy/pleurectomy & 1 & 0 & 0 & 0 \\
\hline
\end{tabular}

Table 2 Cell types and $p$ TNM staging in all patients $(n=125)$ and those who underwent complete resection $(n=86)$

\begin{tabular}{lrl}
\hline & $\begin{array}{l}\text { All } \\
\text { patients } \\
(n=125)\end{array}$ & $\begin{array}{l}\text { Patients with } \\
\text { complete resection } \\
(n=86)\end{array}$ \\
Variable & & \\
Cell type & & \\
Squamous cell carcinoma & 69 & 48 \\
Adenocarcinoma & 42 & 30 \\
Adenosquamous carcinoma & 13 & 7 \\
Large cell carcinoma & 1 & 1 \\
pTNM staging & 71 & 52 \\
pT3N0M0 & 2 & 0 \\
pT3N0M1 & 24 & 19 \\
pT3N1M0 & 1 & 0 \\
pT3N1M1 & 25 & 15 \\
pT3N2M0 & 1 & 0 \\
pT3N3M0 & 1 & 0 \\
pT3NxM0 & & \\
\hline
\end{tabular}

wise, the decision as to which operative procedure should be performed was made peroperatively by the surgeon. Extrapleural dissection was performed when the parietal pleura was easily removed from the ribs, but en bloc resection was used when there was fixation of the tumour to the thoracic wall.

Follow up was completed in all patients in January 1995. Survival was estimated from the date of the operation using the Kaplan-Meier survival analysis method. ${ }^{9}$ Hospital deaths were excluded. Differences in observed survival between groups were tested for statistical significance using the log rank test. ${ }^{10}$ Incremental risk factors affecting survival were evaluated using Cox's proportional hazards model. ${ }^{11}$

\section{Results}

Cervical mediastinoscopy was negative in 112 patients $(89.6 \%)$. Eight patients had positive lymph nodes at mediastinoscopy. The decision to proceed to surgery in these cases was based

Table 3 Depth of chest wall invasion in all patients $(n=125)$ and in those who underwent complete resection $(n=86)$

\begin{tabular}{llllll}
\hline & \multicolumn{2}{l}{ All patients } & & \multicolumn{2}{l}{$\begin{array}{l}\text { Patients with complete } \\
\text { resection }\end{array}$} \\
\cline { 2 - 3 } Invasion of chest wall & $\begin{array}{l}\text { Extrapleural } \\
(n=73)\end{array}$ & $\begin{array}{l}\text { En bloc } \\
(n=52)\end{array}$ & & $\begin{array}{l}\text { Extrapleural } \\
(n=45)\end{array}$ & $\begin{array}{c}\text { En bloc } \\
(n=41)\end{array}$ \\
\hline Parietal pleura & 60 & 12 & & 44 & 9 \\
Intercostal muscles and/or ribs & 13 & 39 & & 1 & 32 \\
Transverse processes & 0 & 1 & & 0 & 0 \\
\hline
\end{tabular}

on their young age in four patients, a single positive lymph node at the ipsilateral tracheobronchial angle in three patients, and at the patient's own request in the remaining case. Cervical mediastinoscopy was not performed in five patients. Table 1 shows the extent of pulmonary resection. In one patient who had a bullectomy and pleurectomy because of persistent pneumothorax the tumour was an incidental finding at pathological examination. One patient underwent combined lobectomy and coronary artery revascularisation.

In 52 patients a combined en bloc resection of the carcinoma and chest wall was performed. The number of resected ribs ranged from one to four: one in 10 patients, two in 20 patients, three in 14 patients, and four in eight patients. Reconstruction of the chest wall with Marlex mesh was necessary in 11 of 52 patients. No prosthetic materials were used in any other instance to fill the defect. There were no wound complications. Resection was judged to be complete in 41 patients. The remaining 73 patients underwent an extrapleural dissection which was complete in 45 patients.

The tumour was opened by chance peroperatively in 12 of 125 patients.

Table 2 shows tumour cell type and pTNM staging of all patients and those with complete resection. One patient who had a bullectomy and pleurectomy was staged as T3NxM0 because he had no cervical mediastinoscopy and no lymph nodes were sampled peroperatively.

The depth of chest wall invasion is shown in table 3 . In the group of 72 patients with only parietal pleura involvement a complete resection was obtained in 44 patients who underwent extrapleural dissection and in nine patients who had en bloc resection. Extrapleural dissection was incomplete at the parietal pleura in four patients. The remaining 12 patients had an incomplete resection because of positive resection margins at the bronchus, tumour involvement of adjacent organs or of mediastinal lymph nodes, or distant metastases. In patients who underwent en bloc resection three resections were judged to be incomplete because of positive mediastinal lymph nodes or a positive resection margin at the subclavian artery.

Tumour involvement extended beyond the parietal pleura in 53 patients. An extrapleural dissection was performed in 13 patients which was incomplete in 12. In two patients postoperative biopsy specimens of the thoracic wall showed tumour involvement, although the surgeon was certain that all tumour had been removed. Complete resection was achieved in 32 patients who underwent en bloc resection and in one who underwent extrapleural dissection. In this patient, who had involvement of the intercostal muscles and the periosteum of the second rib, an extrapleural dissection with resection of the periosteum and part of the intercostal muscles was performed which was judged to be complete. Three patients received preoperative radiotherapy ( $30 \mathrm{~Gy}$ ) to reduce the size of the tumour. 
Postoperative radiation therapy was given to 60 patients in doses of 27-66 Gy. Thirty three patients who had complete resection received postoperative radiotherapy. Thirteen of these had mediastinal lymph node metastases and all were treated with postoperative radiotherapy at the mediastinum and chest wall. The remain-

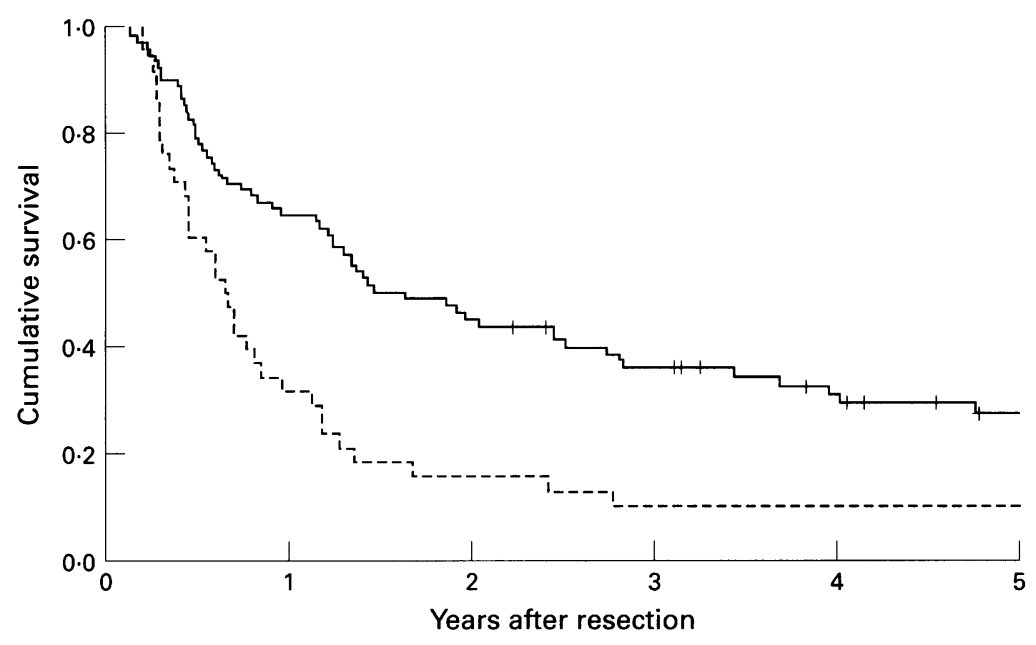

Figure 1 Estimated mean five year survival in patients with complete resection (-) and incomplete resection $(----) .+=$ censored cases.

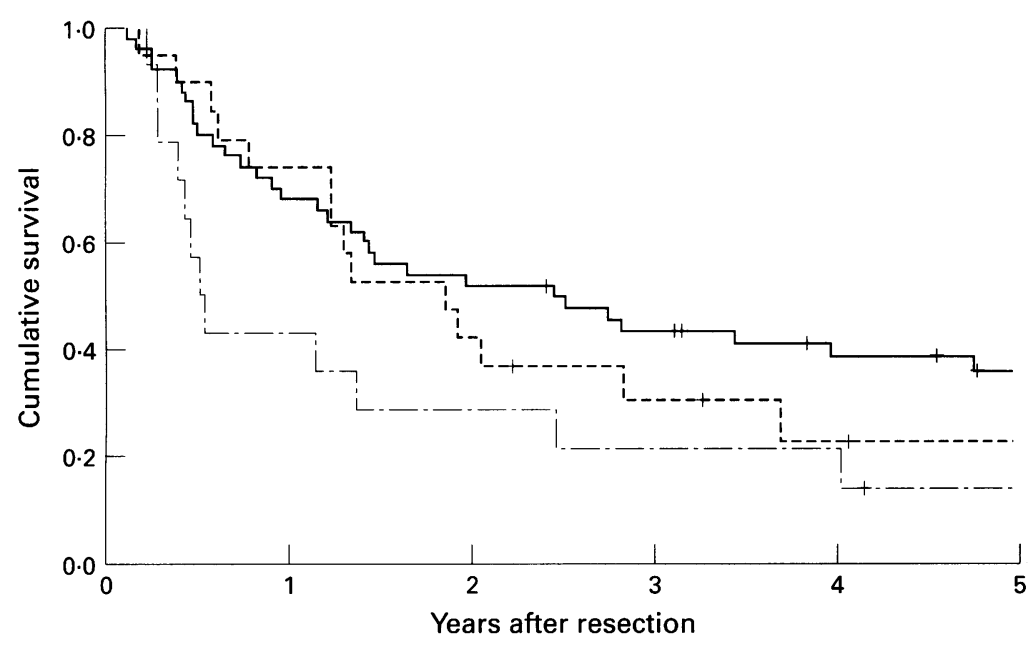

Figure 2 Estimated mean five year survival following complete resection with (N1 - - - , N2 - . . . ) and without (NO $\longrightarrow$ ) lymph node involvement. $+=$ censored cases.

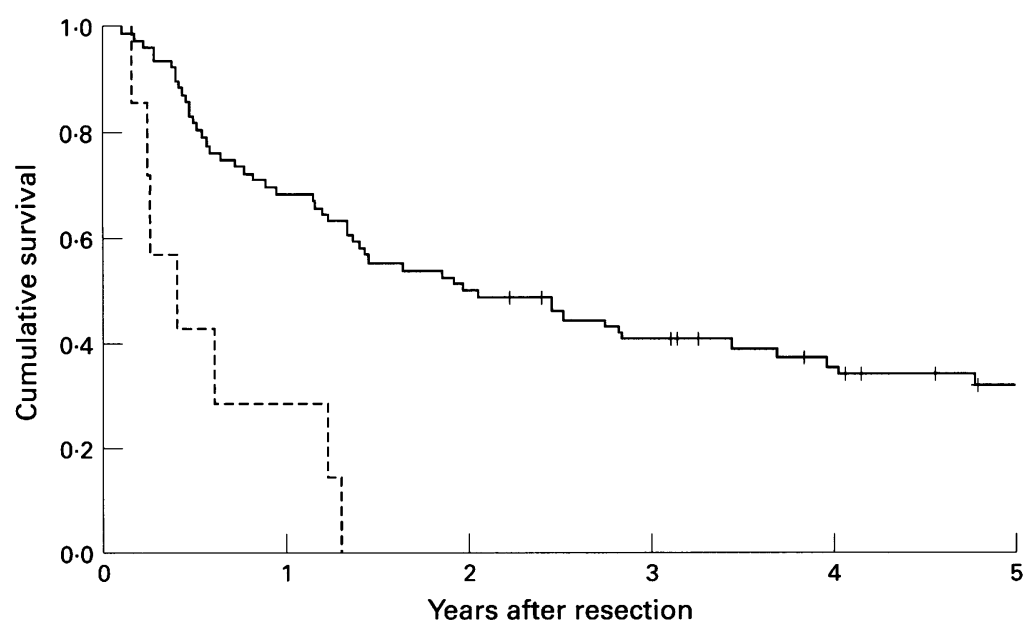

Figure 3 Estimated mean five year survival following complete resection with (- - ) and without $(-)$ intrapleural tumour spill. $+=$ censored cases. ing 27 patients were irradiated postoperatively at the mediastinum and the chest wall because of incomplete resection.

Preoperative chemotherapy was given to one patient who had a positive ipsilateral paratracheal lymph node at cervical mediastinoscopy. Four patients received postoperative chemotherapy because of incomplete resection $(n=3)$ and lung metastases $(n=1)$.

The overall hospital mortality was $3.2 \%$ ( $n=$ 4). Two deaths were due to respiratory failure, one to sepsis, and one to myocardial infarction. Three deaths followed extrapleural dissection and one followed en bloc resection. All these patients had a lobectomy. The estimated mean five year survival for all 125 patients was $23 \%$, and for hospital survivors $(n=121)$ it was $24 \%$.

Complete resection was achieved in 83 hospital survivors $(68.6 \%)$ and these patients had a mean five year survival of $29 \%$. Thirty eight patients who had an incomplete resection had a mean five year survival of only $11 \%$ (p $<0.001$ ) (fig 1).

Because of the significant difference in survival between hospital survivors who underwent complete and incomplete resection, it was decided to analyse only the results of those 83 who had complete resection with regard to other survival characteristics. In the univariate analysis survival was strongly related to mediastinal lymph node involvement. The mean five year survival for patients with N0 tumours was $36 \%$ compared with $23 \%$ and $14 \%$, respectively, for those with $\mathrm{N} 1$ and $\mathrm{N} 2$ tumours. The difference between N0 and N2 tumours was statistically significant ( $p<0.05)$ (fig 2$)$.

Similarly, survival was related to spill of tumour (fig 3). The tumour was opened peroperatively in seven of 121 hospital survivors, all of whom died within 16 months because of distant metastases $(n=4)$, respiratory failure $(n=2)$, and local recurrence $(n=$ 1). Patients without intrapleural tumour spill had a mean five year survival of $32 \%$ ( $p$ $<0.0001$ ).

Patients with adenocarcinoma had a better mean five year survival $(40 \%)$ than those with squamous cell carcinoma (26\%), although the difference was not statistically significant. Age, depth of chest wall involvement, and type of operative procedure did not significantly influence survival.

The use of postoperative radiotherapy had no statistically significant effect on survival in our series, neither for patients who underwent en bloc resection nor for those who had extrapleural dissection.

According to the multivariate analysis, sex, intrapleural tumour spill, and mediastinal lymph node involvement were identified as prognostic factors (table 4).

Local recurrence of malignancy was found in 13 of 83 hospital survivors who underwent complete resection (15.7\%), eight after en bloc resection, and five after extrapleural dissection.

\section{Discussion}

In this study the overall hospital mortality of $3.2 \%$ is similar to the results of McCaughan et $a l^{3}$ but lower than other reports..$^{6712-15}$ En bloc 
Table 4 Proportional hazards regression model based on 83 patients with complete resection

\begin{tabular}{|c|c|c|c|c|}
\hline Variable & $\beta$ & $S E$ & $\begin{array}{l}\text { Hazard } \\
\text { ratio }\end{array}$ & $95 \% C I$ \\
\hline $\operatorname{Sex}^{*}$ & 0.78 & 0.38 & 2.17 & 1.04 to 4.53 \\
\hline Tumour spill”* & -1.51 & 0.36 & 0.22 & 0.11 to 0.44 \\
\hline pTNM $^{\dagger}$ & 0.14 & 0.30 & 1.15 & 0.64 to 2.07 \\
\hline pTNM $^{\text {tt }}$ & 0.89 & 0.26 & 2.43 & 1.45 to 4.08 \\
\hline
\end{tabular}

$\beta=$ regression coefficient; $S E$ = standard error; CI = confidence interval; * men versus women; * no versus yes; $†$ pT 3 N1M0 versus $\mathrm{pT} 3$ N0M0; + pT 3 N2M0 versus pT3NOMO.

resection had no higher mortality rate $(1.9 \%)$ than extrapleural dissection (4.1\%). Our estimated mean five year survival for 121 hospital survivors of $24 \%$ is similar to the results of others, ${ }^{5-7} 12$ but less than those achieved by Patterson et $\mathrm{ll}^{13}$ and McCaughan et al. ${ }^{3}$ The retrospective nature of our study sometimes made it difficult to trace former treatment strategies.

The choice of extrapleural dissection or en bloc resection is an important factor in the treatment of lung cancer with chest wall invasion. Some authors favour en bloc resection of the carcinoma and chest wall, ${ }^{5614}$ whereas others have found no difference between the two procedures. ${ }^{3712}$ However, comparison of these studies is difficult because of differences in patient selection, operative procedures, and statistical analysis. In this series there was no difference in mean five year survival between patients undergoing en bloc resection or extrapleural dissection when only the parietal pleura was involved. When invasion of the thoracic wall was proven preoperatively by pathological examination en bloc resection was planned, otherwise the choice of operative procedure was made peroperatively. When the parietal pleura could be easily dissected from the ribs an extrapleural dissection was carried out, but when there was fixation of the tumour to the thoracic wall or when pathological examination showed positive resection margins en bloc resection was performed. However, six patients had positive resection margins at the parietal pleura although the surgeon was certain during the operation that all tumour was removed. This indicates that pathological examination of resection margins should always be carried out peroperatively and that, if there is any doubt about complete resection, an en bloc resection should be performed whenever possible.

As is generally recognised, ${ }^{3-7}{ }^{12-15}$ mediastinal lymph node involvement indicates an unfavourable prognosis. Mean five year survival for patients with N0 tumours was $36 \%$, compared with $23 \%$ and $14 \%$ for N1 and N2 tumours, respectively. The difference between $\mathrm{NO}$ and N2 tumours was statistically significant.

The tumour was opened peroperatively in seven patients and none of these patients lived more than 16 months. The difference in mean five year survival between patients with and without intrapleural tumour spill was significant $(0 \%$ and $32 \%$, respectively). In our study these seven patients were judged to have had a complete resection but, because of their poor prognosis, we believe that intrapleural tumour spill must be regarded as incomplete resection.

Histological examination showed a higher incidence of squamous cell carcinoma (55.2\%). Patients with adenocarcinoma had a better mean five year survival than those with squamous cell carcinoma $(40 \%$ and $26 \%$, respectively), although the difference was not significant. The fact that adenocarcinomas are often located more peripherally and thus cause earlier complaints of chest pain may be a reason for this difference in survival.

Unlike McCaughan et $a l^{3}$ other studies reported no relation between depth of chest wall invasion and survival ${ }^{7}$ and our results are in agreement with this finding. Patients who underwent en bloc resection had no difference in mean five year survival when there was tumour involvement in or beyond the parietal pleura.

The indications for radiotherapy in resected T3 lung cancer with chest wall involvement remain unclear. Some authors ${ }^{13} 16$ have described a better survival in patients who have radiotherapy while others have reported no difference. $^{515} 17$ In this study preoperative radiotherapy was only given to three patients so we cannot comment on its efficacy. Sixty patients received postoperative radiotherapy, 27 of whom underwent incomplete resection and 33 complete resection. In the latter group no significant relationship was found between survival and postoperative radiotherapy, but it must be borne in mind that this is a non-randomised series.

No relationship was found between operative procedure and local recurrence. Thirteen patients who underwent complete resection had local recurrence compared with five patients after extrapleural dissection and eight after en bloc resection.

We conclude that complete resection in patients with T3 lung cancer involving the chest wall yields good survival results after either en bloc resection or extrapleural dissection. Both surgical techniques can be performed safely and invasion of the parietal pleura is not a contraindication to extrapleural dissection.

Mediastinal lymph node involvement, incomplete resection, and intrapleural tumour spill, however, imply an unfavourable prognosis. Postoperative irradiation, age, and depth of chest wall invasion do not influence survival significantly.

We wish to thank Mrs Joke van der Sluis for her secretarial support. The study was supported by a grant from the Mr. Willem Bakhuys Roozeboom Foundation.

1 Grillo HC, Greenberg JJ, Wilkins EW. Resection of bronchogenic carcinoma involving thoracic wall. $\mathcal{f}$ Thorac Cardiovasc Surg 1966;51:417-21.

2 Geha AS, Bernatz PE, Woolner LB. Bronchogenic carcinoma involving the thoracic wall. Surgical treatment and prognostic significance. $\mathcal{F}$ Thorac Cardiovasc Surg 1967; 54:394-402.

3 McCaughan BC, Martini N, Bains MS, McCormack PM. Chest wall invasion in carcinoma of the lung. Therapeutic
and prognostic implications. $\mathcal{f}$ Thorac Cardiovasc Surg and prognostic

4 Coleman FP. Primary carcinoma of the lung with invasion of the ribs: pneumonectomy and simultaneous block resection of the chest wall. Ann Surg 1947;126:156-68. 
5 Allen MS, Mathisen DJ, Grillo HC, Wain JC, Moncure AC, Hilgenberg AD. Bronchogenic carcinoma with chest wall invasion. Ann Thorac Surg 1991;51:948-51.

6 Albertucci M, DeMeester TR, Rothberg M, Hagen JA, Santoscoy R, Smyrk TC. Surgery and the management of peripheral lung tumors adherent to the parietal pleura. $\mathcal{F}$ Thorac Cardiovasc Surg 1992;103:8-13.

7 Lopez L, Lopez-Pujol J, Varela A, Baamonde C, Socas L, Salvatierra A, et al. Surgical treatment of stage III non-small cell bronchogenic carcinoma involving the chest wall Scand F Thorac Cardiovasc Surg 1992;26:129-33.

8 Mountain CF. A new international staging system for lung cancer. Chest 1986;89:225s-33s.

Kaplan EL, Meier P. Non-parametric estimation from incomplete observations. F Am Stat Assoc 1958;53:457-81.

10 Peto R, Peto J. Asymptotically efficient rank invariant test procedures. F $R$ Statist Soc (series A) 1972;135:185-98.

11 Cox DR. Regression models and life tables. $\mathcal{F} R$ Statist Soc (series B) 1972;34:187-202.

12 Casillas M, Paris F, Tarrazona V, Padilla J, Paniagua M, Galan G. Surgical treatment of lung carcinoma involving the chest wall. Eur f Cardiothorac Surg 1989;3:425-9.
13 Patterson GA, Ilves R, Ginsberg RJ, Cooper JD, Todd TRJ, Pearson FG. The value of adjuvant radiotherapy in pulmonary and chest wall resection for bronchogenic carcinoma. Ann Thorac Surg 1982;34:692-7.

14 Trastek VF, Pairolero PC, Piehler JM, Weiland LH, O'Brien PC, Payne WS, et al. En bloc (non-chest wall) resection for bronchogenic carcinoma with parietal fixation. Factors affecting survival. If Thorac Cardiovasc Surg 1984; 87:352-8.

15 Piehler JM, Pairolero PC, Weiland LH, Offord KP, Payne WS, Bernatz PE. Bronchogenic carcinoma with chest wall invasion: factors affecting survival following en bloc resection. Ann Thorac Surg 1982:34:684 91.

16 Carrel F, Nachbur B, Veraguth P. En bloc resection for bronchogenic carcinoma with chest wall invasion. Eur f Cardiothorac Surg 1990;4:534-7.

17 Paone JF, Spees EK, Newton CG, Lillemoe KD, Kieffer RF, Gadacz TR. An appraisal of en bloc resection of peripheral bronchogenic carcinoma involving the thoracic wall. Chest 1982;81:203-7. 